\title{
Orbital metastasis from anorectal carcinoma
}

\author{
Pavan Kumar Lachi ${ }^{1}$, Megha S. Uppin², Monica Irukulla ${ }^{1}$, Kotiyala V. Jaganadha Rao Naidu ${ }^{1}$ \\ ${ }^{1}$ Department of Radiation Oncology, Nizam's Institute of Medical Sciences, Hyderabad 500082, Telangana, India. \\ ${ }^{2}$ Department of Pathology, Nizam's Institute of Medical Sciences, Hyderabad 500082, Telangana, India.
}

Correspondence to: Dr. Pavan Kumar Lachi, Department of Radiation Oncology, Nizam's Institute of Medical Sciences, Hyderabad 500082,

Telangana, India. E-mail: drpavan.lachi@gmail.com

\section{A B S T R A C T}

Pulmonary and liver metastases are common sites of distant metastasis from the rectal carcinoma. Metastases to the head and neck region are uncommon from carcinoma of the rectum, and orbital metastases are extremely rare. Here, we describe a 27-year-old female, who was diagnosed as a case of anorectal carcinoma in April 2010. She underwent abdominoperineal resection followed by concurrent chemoradiotherapy and adjuvant chemotherapy with 5 fluorouracil and leucovorin on follow-up. In January 2012, she presented with gradually increasing swelling over the left temporal region and left sided proptosis. Fine-needle aspiration and a cell block were performed. Metastasis was confirmed histologically. Palliative radiotherapy to the left orbit at the dose of 3 Gy per fraction 10 fractions to a total dose of 30 Gy was given by cobalt-60. In patients with a history of rectal carcinoma, recent onset proptosis with temporal swelling, although rare, should raise suspicion of metastatic deposit.

Key words: Anorectal carcinoma, distant metastasis, orbital metastasis

\section{Introduction}

Colorectal cancer is the third most common cancer with more than one million new cases each year worldwide. However, metastases from colorectal cancer to the orbit are exceedingly rare. ${ }^{[1,2]}$ We report here, in the first patient from the India with such a presentation. The reason for the rarity of colorectal metastases to the eye and orbit is not clear but may be related to anatomical barriers and routes of metastasis.

\section{Case Report}

A 27-year-old female initially presented in April 2010 with complaints of bleeding per rectum for 8 months, altered bowel habit and spurious diarrhea for 4 months. Rectal examination revealed a polypoidal mobile growth $3 \mathrm{~cm}$ from anal verge on the lateral and posterior wall of the rectum. Colonoscopy showed a friable circumferential growth in the rectum. Anorectal margin appeared to be involved by the tumor. Biopsy showed features consistent with adenocarcinoma, with surface ulceration. Contrast-enhanced computed tomography (CT) of the abdomen revealed an irregular wall thickening and enhancement involving the anorectal region with perifocal fat stranding and small volume $(6 \mathrm{~mm} \times 5 \mathrm{~mm})$ lymph node in pelvis on left with involvement of

\begin{tabular}{|l|l|}
\hline \multicolumn{2}{|c|}{ Access this article online } \\
\hline Quick Response Code: & Website: \\
\hline
\end{tabular}

anorectal sphincter. Permanent sigmoid colostomy and abdominoperineal resection were done. Intraoperative findings were an ulceroproliferative, circumferential growth of $6 \mathrm{~cm} \times 5 \mathrm{~cm}$ in the lower rectum, $4 \mathrm{~cm}$ from anal verge; there was no evidence of lymph node involvement and no ascites. Post-operative histopathology showed well-differentiated adenocarcinoma, extending into serosa, pT3, pN2 (7/11), $5 \mathrm{~cm} \times 5 \mathrm{~cm} \times 1 \mathrm{~cm}$, $7.5 \mathrm{~cm}$ from proximal margin, $4 \mathrm{~cm}$ from distal margin, with foci of perineural invasion, and lymphovascular invasion. Carcinoembryonic antigen (CEA) was $32.5 \mathrm{ng} / \mathrm{mL}$ (normal 4-7 ng/mL). Post-operative adjuvant chemo-radiotherapy was given to the whole pelvis in anteroposterior and posteroanterior fields 2 Gy per fraction, 25 fractions to a total dose of 50 Gy by cobalt-60. During radiotherapy, 2 cycles of concurrent chemotherapy with 5 fluorouracil plus leucovorin were given on D1-D5 and D21-D25, followed by 4 cycles of adjuvant chemotherapy, with the last cycle given in November 2010. CEA (January 8, 2011) was $3.4 \mathrm{ng} / \mathrm{mL}$. Twenty-one months later, she presented with swelling over the left temporal region and left eye proptosis [Figure 1]. On examination, there was a $5 \mathrm{~cm} \times 3 \mathrm{~cm} \times 4 \mathrm{~cm}$ swelling over the left temporal region, with ill-defined borders on palpation, firm-to-hard in consistency and with no signs of local inflammation. Asymmetrical proptosis of the left eye was noted. The vision was normal in both eyes. No focal neurological deficit was noted. CT scan of the skull, soft tissues, and brain showed a mixed density mass along the lateral wall of the left retro-orbital area, adherent to the optic nerve [Figure 2]. Fine-needle aspiration cytology and biopsy were suggestive of metastatic adenocarcinoma [Figure 3]. Bone scan showed increased uptake in the left orbital region, right sacroiliac joint 


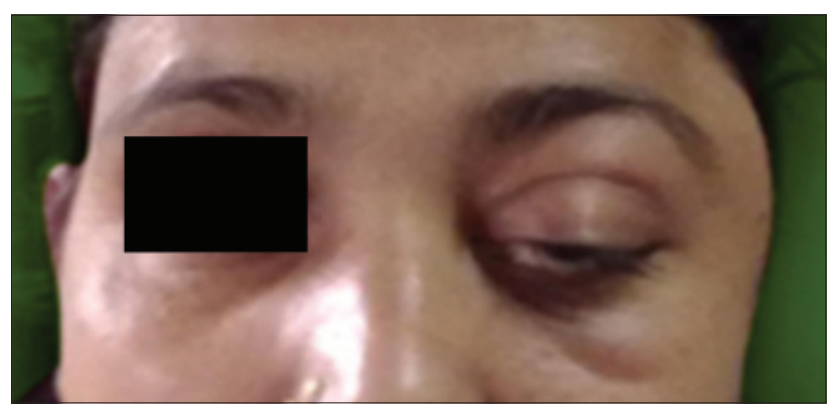

Figure 1: $5 \mathrm{~cm} \times 3 \mathrm{~cm} \times 4 \mathrm{~cm}$ swelling over left temporal region

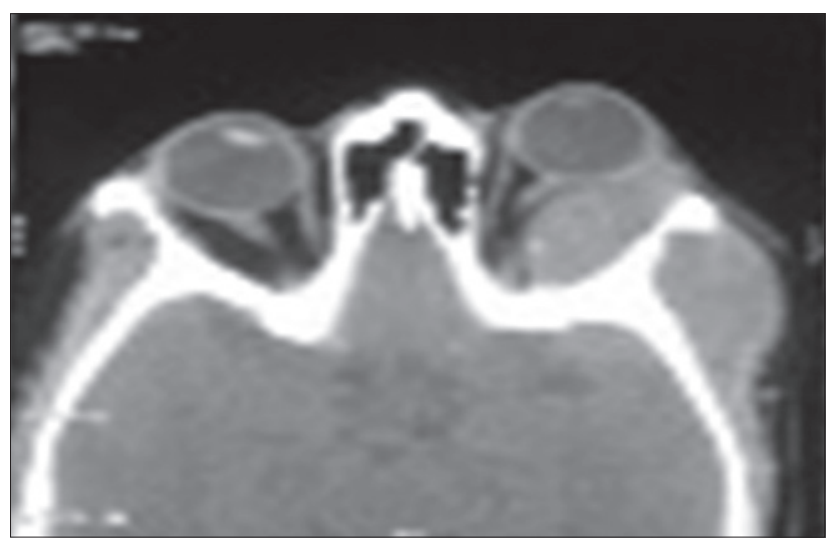

Figure 2: Computed tomography scan showing a mixed density mass along lateral wall of left retro-orbital area, adherent to optic nerve

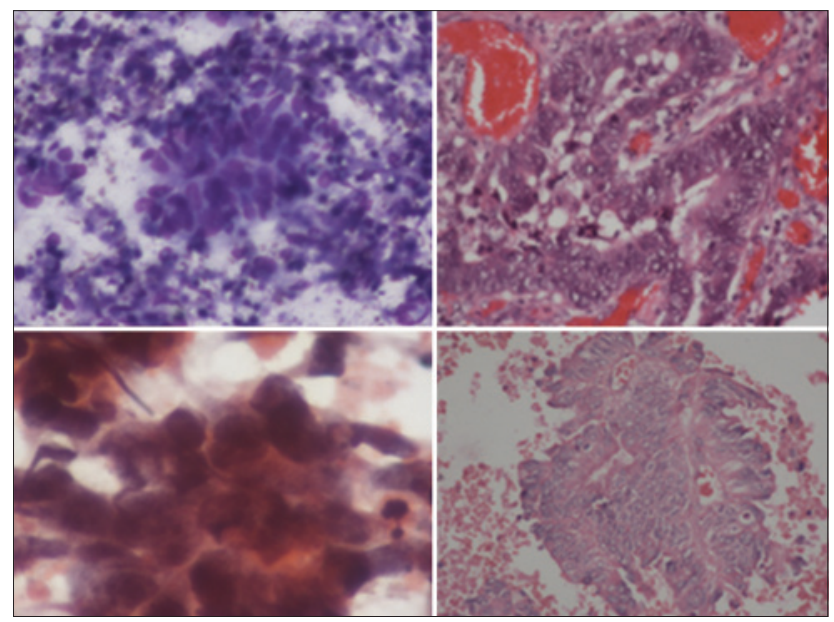

Figure 3: Morphology showing papillae and acinar pattern of columnar cells with moderate cytoplasm, oval nucleus, increased nuclear-cytoplasmic ratio and second lumbar vertebral body, and suggestive of metastatic disease. Therefore, the patient was diagnosed with rectal carcinoma with multiple distant metastases. Palliative radiotherapy to the left orbit, lumbar spine, and right hemipelvis was given. The patient agreed to publish her pictures and signed the consent form.

\section{Discussion}

Rectal carcinoma in the young is increasing in incidence. This may be associated with familial adenomatous polyposis and hereditary non-polyposis colorectal cancer (Lynch) syndrome. Metastatic tumors to the orbit are rare and most commonly are from lung, breast, prostate, and kidney primaries. Only 5\% are from the gastrointestinal tract. ${ }^{[3,4]}$ A review of the literature revealed only 6 cases reported of primary colorectal malignancy metastasizing to the orbit, with only three showing histopathology. ${ }^{[5]}$ When gastrointestinal cancers metastasize to the orbit, this is usually combined with multiple disseminated metastases. ${ }^{[6]}$ Management of metastatic orbital tumors requires a multidisciplinary team approach including radiotherapy, chemotherapy, and surgery.

\section{References}

1. Chekrine T, Hassouni A, Hatime M, Jouhadi H, Benchakroun N, Bouchbika Z, Tawfiq N, Sahraoui S, Benider A. Orbital metastasis from mucinous adenocarcinoma of the rectum. J Fr Ophtalmol 2013;36:e73-5.

2. Ezra E, Vardy S, Rose G. Metastatic colonic adenocarcinoma of the orbit with intraneural extension from the brow to the brainstem. Eye (Lond) 1995;9 (Pt 3):371-2.

3. Shields JA, Shields CL, Brotman HK, Carvalho C, Perez N, Eagle RC Jr. Cancer metastatic to the orbit: The 2000 Robert M. Curts Lecture. Ophthal Plast Reconstr Surg 2001;17:346-54.

4. Goldberg RA, Rootman J, Cline RA. Tumors metastatic to the orbit: a changing picture. Surv Ophthalmol 1990;35:1-24.

5. Charles NC, Ng DD, Zoumalan CI. Signet cell adenocarcinoma of the rectum metastatic to the orbit. Ophthal Plast Reconstr Surg 2012;28:e1-2.

6. Chen SF, Yii CY, Chou JW. Colon cancer with orbital metastasis. Clin Gastroenterol Hepatol 2011;9:e76-7.

How to cite this article: Lachi PK, Uppin MS, Irukulla M, Jaganadha Rao Naidu KV. Orbital metastasis from anorectal carcinoma. J Cancer Metastasis Treat 2015;1:104-5.

Received: 13-01-2015; Accepted: 11-05-2015.

Source of Support: Nil, Conflict of Interest: None declared. 